\title{
Aspects of Fatal Burn Injury Cases Admitted to Al-Sadiq Teaching Hospital, Babylon Province/Iraq During 2020
}

\author{
Elaf Mohammed Obaid ${ }^{1}$, Hasan Alwan Baiee ${ }^{2}$, Issam Salim Ismail ${ }^{3}$ \\ ${ }^{1}$ High Diploma Student/Family Medicine-Medical College-University of Babylon/Iraq, ${ }^{2}$ Prof. University of \\ Babylon-Hammurabi, College of Medicine/Iraq, ${ }^{3}$ Specialist/Dr. Wasit Health Directorate/Iraq
}

\begin{abstract}
Background: Burns death both intentional and non-intentional considered among the most disastrous outcome of burn injuries.

Objectives: To measure the case fatality rate in hospitalized burn patients and to investigate in-hospital mortality among burn injury cases who were admitted to Al-Sadiq Teaching Hospitalburn center from the first of January to the end of June, 2020.

Methodology: This is an observational descriptive case series study conducted on all cases who died from burn injury among patients who were admitted to the biggest teaching hospital in Babylon Province - Iraq. Data were collected from patients themselves or their companions and from patients' hospital records, using a pretested questionnaire designed for collection the requested information.

Results: The mean age \pm SD (Standard Deviation) of burn death victims were $24.5 \pm 17.66$ years. Young age group (15-24 years) represents the highest proportion (50\%). Male to female ratio was 1:2.25. The case fatality rate was $26.6 \%(32 / 120)$. The majority of cases were from rural areas, $67 \%$ of suicidal burn deaths had more than $50 \%$ of burnt total body surface area. Intentional burn deaths victims had significantly severe burns (third degree burn and high-burnt surface area) as compared to accidental burn deaths. There was a statistically significant difference as regards the mode of burns between the intentional and accidental burn deaths, all intentional deaths were burnt with flame.
\end{abstract}

Conclusions: The case fatality rate of burn injuries was high, females outnumbered males, and suicidal burn deaths were significantly associated with severe burn as compared to the accidental ones.

Keywords: Intentional burn injury deaths, accidental burn deaths, Babylon, Iraq.

\section{Introduction}

According to World health Organization, fire burns were responsible for more than 300,000 deaths annually ${ }^{(1)}$. Burns still represent one of the leading cause of death in developing countries ${ }^{(2)}$.

\section{Corresponding Author:}

Hasan Alwan Baiee

Prof. University of Babylon-Hammurabi, College of

Medicine/Iraq

e-mail: hassanbaey@yahoo.com
Recently, developed countries have made good progress in lowering burn-related mortality including Self Inflicted Burn (SIB) by raising awareness, prevention, improving secondary and tertiary health care and support programs for SIB cases ${ }^{(3)}$ but SIB is still a priority public health problem in developing countries, including $\operatorname{Iraq}^{(4)}$.

Self-burn is high in Asian countries and the lowest in the United States ${ }^{(5,6)}$. This may be associated with the instability of the region, due to insecurity and the continuous arm conflicts. The rates of SIB associated burn deaths were very high $85 \%$ in Pakistan ${ }^{(7)}, 79.6 \%$ in $\operatorname{Iran}^{(8)}$, and high $60 \%$ in $\mathrm{Nepal}^{(9)}$ while the rates of 
deaths are low in Brazil 40\% ${ }^{(10)}$ and Sri Lanka $27 \%^{(11)}$. SIB is generally more common among females than among males ${ }^{(12)}$.

The majority of burn death cases were accidental, while suicidal manner was mainly observed in females ${ }^{(13-21)}$.

The burden of burn in Baghdad is quite high ${ }^{(22)}$. The objectives of this study are to measure the case fatality rate in hospitalized burn patients and to investigate inhospital mortality among burn injury cases.

\section{Methodology}

This is an observational descriptive case series study conducted on all cases who died from burn injury among patients who were admitted to Al Sadiq Teaching Hospital-Babylon Province-Iraq, this hospital is biggest general teaching hospital in Babylon province, the burn unit includes two wards for males and females. This hospital serves the population of Babylon province, which located in the south central region of Iraq and populated about two million inhabitants. The period of study started from the first of January 2020 to the end of June 2020. Data were collected from patients themselves or their companions and from patients' hospital records, using a pretested questionnaire designed for data collection. Acceptance from the University of Babylon Ethical Committee, College of Medicine and the director of Babylon Health Directorate were taken. Informed verbal consents were obtained from the patients' companions or their families, the confidentiality was ensured by keeping all records anonymous. Data include socio-demographic data (age, gender, level of education) types of burn and etiology of burn.

Burns can be; partial thickness burns (second degree) extend through the epidermis and into the dermis or full-thickness burns (third degree) extend through the subcutaneous fat or deeper ${ }^{(23,24)}$. When estimating the degree of burn in this study, only partial thickness and full thickness burns are considered, and superficial burns are excluded. The extent of burn injury determined by the total body surface area (TBSA) in which estimated according to the rule of nine ${ }^{(25)}$.

\section{Results}

A (32) dead cases included in this study out of 120 burn injured patients. The case fatality rate was $(26.6 \%)$. Burn mortality higher in females than in males, OR with $95 \%$ CI $(2.78 ; 1.16-6.72)$ P 0.019 . Death doubled in those aged $>18$ years old than in children aged $\leq 18$ years, OR with 95\% CI $(3.03 ; 1.30-7.06)$ P 0.009 . Half of patients with $3^{\text {rd }}$ degree burn injuries and mixed burn were dead, while $97 \%$ of those with $2^{\text {nd }}$. degree were cured, OR with 95\% CI (30.5 6.81-136.6) P 0.0001, table [1].

\section{Table 1: Association between demographic characteristics and burn degree with the outcome of burn injuries $(\mathbf{N}=120)$.}

\begin{tabular}{|c|c|c|c|c|c|}
\hline \multirow{2}{*}{\multicolumn{2}{|c|}{ Variables }} & \multicolumn{2}{|c|}{ Outcome $(\mathrm{N}=120)$} & \multirow{2}{*}{ OR $(95 \% \mathrm{CI})$} & \multirow{2}{*}{ Sig.* } \\
\hline & & \multirow{2}{*}{$\begin{array}{c}\text { Cured (n=88) } \\
46(84 \%)\end{array}$} & \multirow{2}{*}{$\begin{array}{c}\text { Dead }(\mathbf{n}=\mathbf{3 2}) \\
9(16 \%)\end{array}$} & & \\
\hline \multirow{2}{*}{ Gender } & Male & & & \multirow{2}{*}{$2.78(1.16-6.72)$} & \multirow{2}{*}{0.019} \\
\hline & Female & $42(65 \%)$ & $23(35 \%)$ & & \\
\hline \multirow{2}{*}{ Age groups (years) } & $\leq 18$ & $54(83 \%)$ & $11(17 \%)$ & \multirow{2}{*}{$3.03(1.30-7.06)$} & \multirow{2}{*}{0.009} \\
\hline & $>18$ & $34(62 \%)$ & $21(38 \%)$ & & \\
\hline \multirow{2}{*}{ Burn degree } & $2^{\text {nd }}$ & $59(97 \%)$ & $2(3 \%)$ & \multirow{2}{*}{$30.5(6.81-136.6)$} & \multirow{2}{*}{0.0001} \\
\hline & $3^{\text {rd }}$ and mixed & $29(49 \%)$ & $30(51 \%)$ & & \\
\hline
\end{tabular}

* Chi-Square Test

The mean age \pm SD (standard deviation) of burn death victims are $24.5 \pm 17.66$ years, ranged $(1.5-83$ years). Young age group (15-24 years) represents $50 \%$ of burning deaths, as shown in figure [1]. Male to female ratio 1:2.25 (P 0.013), figure [2]. 


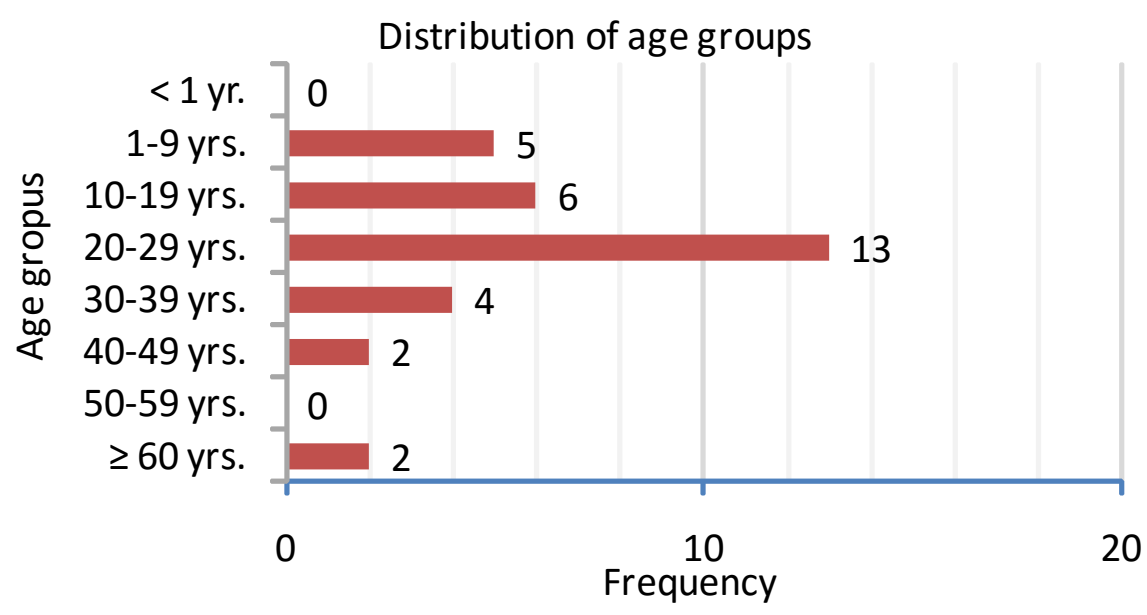

Figure 1: Frequency distribution of sample according to age groups $(\mathrm{N}=32)$.

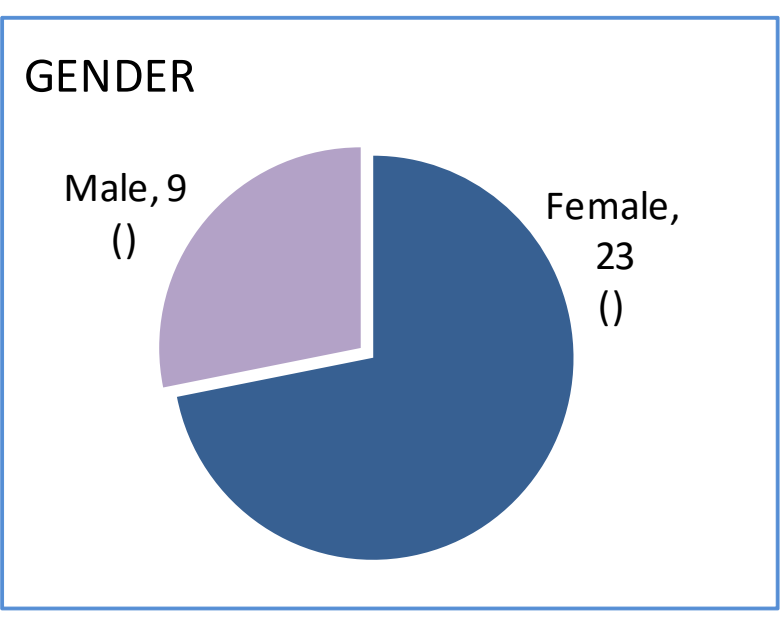

Figure 2: Gender distribution $(\mathrm{N}=32)$

Concerning the marital status, $59 \%$ of them and $15.6 \%$ are single. The majority $(87 \%)$ of victims have intermediate school achievement or less, and $62 \%$ of them have not enough monthly income. Only three (9\%) of victims present with past medical history, and one case $(3 \%)$ present with history of mental illness. Five cases $(16 \%)$ reported tobacco smoking, table [2].

The mean duration of admission to hospital was four days \pm 2.79 SD. Findings indicated that $25 \%, 44 \%$ and $31 \%$ of victims hospitalized for 1 day, $2-5$ days and $>5$ days respectively.

One-half of deaths occurred intentionally by suicide. Suicidal burn deaths patients have severe burns $\left(3^{\text {rd }}\right.$. and mixed degree of burn i.e. third and second degree) while most of accidental burn deaths have less severe (mixed degree patients), two of them occurred in patients with $2^{\text {nd }}$ degree (P 0.051), figure [3].

Table 2: Description of socio-economic characteristics, past medical/mental illness history and risky behavior of the burning death $(\mathrm{N}=32)$.

\begin{tabular}{|l|l|c|c|}
\hline Variables & & Frequency & \% \\
\hline \multirow{4}{*}{ Marital status } & Child $<15$ yrs. & 5 & 45.8 \\
\cline { 2 - 4 } & Single & 5 & 10.8 \\
\cline { 2 - 4 } & Married & 19 & 40 \\
\cline { 2 - 4 } & Divorced & 2 & 1.7 \\
\cline { 2 - 4 } & Widowed & 1 & 1.7 \\
\hline
\end{tabular}




\begin{tabular}{|c|c|c|c|}
\hline Variables & & Frequency & $\%$ \\
\hline \multirow{6}{*}{ Educational level } & Preschool & 5 & 15.6 \\
\hline & Illiterate & 9 & 28.1 \\
\hline & Primary & 8 & 25 \\
\hline & Intermediate & 6 & 18.8 \\
\hline & Secondary & 4 & 12.5 \\
\hline & College & 0 & 0.0 \\
\hline \multirow{3}{*}{ Income adequacy } & Enough & 11 & 34 \\
\hline & Not enough & 20 & 63 \\
\hline & Enough and more & 1 & 3 \\
\hline \multirow{2}{*}{ Past medical history } & Present & 3 & 9 \\
\hline & Absent & 29 & 91 \\
\hline \multirow{2}{*}{ History of mental illness } & Present & 1 & 3 \\
\hline & Absent & 31 & 97 \\
\hline \multirow{2}{*}{ Smoking } & Smoker & 5 & 16 \\
\hline & Non smoker & 27 & 84 \\
\hline
\end{tabular}

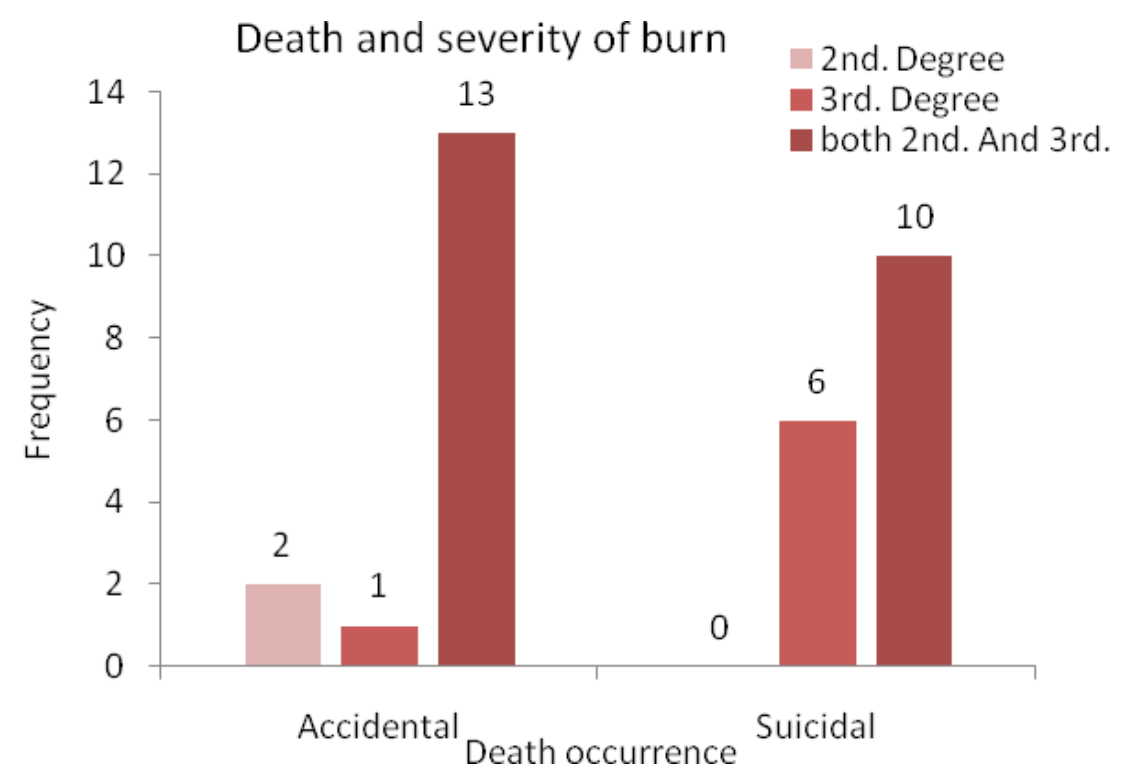

Figure 3: Relationship between suicidal burn deaths and degree of burn $(\mathrm{N}=32)$.

The mean total body surface area was $59.72 \pm 23.8$ SD ranged (24-100\%). More than two-third of patients present with TBSA $\geq 50 \%$. However, suicidal death present with $67.8 \%$ mean TBSA while, accidental death present with 51.5\% mean TBSA (P 0.05). The causes of burn was flame in $81 \%$ of death and 19 by hot liquids, table [2]. All intentional burn deaths occurred by using flame while, two-third of accidental death occurred with flame and one-third by hot liquids (P 0.018).
Table 3: Frequency distribution of total body surface area of burn and the etiology of burn $(\mathrm{N}=32)$

\begin{tabular}{|l|c|c|}
\hline Variables & Frequency & $\mathbf{\%}$ \\
\hline TBSA & & \\
\hline$<10 \%$ & - & - \\
\hline $10-20 \%$ & - & - \\
\hline $21-30 \%$ & 3 & 9 \\
\hline $31-40 \%$ & 6 & 19 \\
\hline
\end{tabular}




\begin{tabular}{|l|c|c|}
\hline Variables & Frequency & \% \\
\hline $41-50 \%$ & 4 & 12 \\
\hline $51-60 \%$ & 7 & 22 \\
\hline$>60 \%$ & 12 & 38 \\
\hline Etiology & & \\
\hline Flame & 26 & 81 \\
\hline Hot liquid & 6 & 19 \\
\hline
\end{tabular}

Findings indicated that $63 \%$ of patients were uninvestigated for microbial infections, Pseudomonas detected in $16 \%$ of patients, negative microorganisms detected in $9 \%$ of the sample and Staphylococcus aurous detected in $6 \%$ of them.

\section{Discussion}

The current study is undertaken to describe the characteristics of hospitalized burn deaths. The case fatality rate in this study is relatively high as compared to the results reported by other national studies conducted in Diqar, Basrah, Musol, Baghdad and Babylon governorates ${ }^{(12-14,22 ; 26-28)}$. The fatality rate in this study is higher than rate reported by Kandeel FS (13.3\%) and El Mehrat et al in Menoufia University Hospital, Egypt ${ }^{(19,20)}$ and that reported in Jordan ${ }^{(29)}$. But it was very much higher than that reported by Krishnan et al. from the United Kingdom ${ }^{(30)}$ who noted mortality rate $1.9 \%$. These differences may be due to the nature of these societies as they have better health care services with higher level of public awareness, this comparison should bring the attention of health care planner in Babylon governorate to develop much better health care facilities.

Females are outnumbered among self-inflict burn victims in this study at their young age, this finding goes in line with the findings of other studies ${ }^{(26,31,32)}$. In a qualitative study carried out by Gatea et al in Baghdad on thirty SIB women in their reproductive age they found that females who committed suicide using burn specially fire have four problems leading to this burn deaths these included; personal, social, economic and family situation of the victims. Among these, the main identified factors, family pressure, unstable families, and poor mental health ${ }^{(33)}$.Females at home may find a fire as weapon to end their lives by burn instead of suffering in male dominated poor societies ${ }^{(31)}$. In our study most of the victims had low level of education, this finding is similar to that reported by other researchers; Gadge et al. concluded that most of self-inflicted burn victims had middle school level of education ${ }^{(34)}$ while Gupta et al. showed that the majority of victims had primary school level ${ }^{(35)}$.

Most of the victims belong to low socioeconomic class this finding consistent with the finding of Vaghela et al. who reported that most of cases were in low socio economic status ${ }^{(36)}$. The majority of victims in this study had more than $50 \%$ burnt total body surface area. The risk of death usually increased burnt surface areas as this indicates the incompatibility with life ${ }^{(37)}$.

Suicidal burn deaths patients have severe burns $\left(3^{\text {rd }}\right.$. and mixed degree of burns) while most of accidental burn deaths have less severe degree of burns and the majority of cases were mainly from rural areas. These findings are consistent with the finding of other studies ${ }^{(19,38)}$.

Suicidal manner was observed in half of the victims this percentage is much higher than that reported by similar study conducted in Egypt which revealed that the majority of cases were accidental burn deaths ${ }^{(19)}$ but, our finding agrees with the finding of Nath et al. (2015) in India, which revealed that the majority of deaths were suicidal in nature followed by homicidal and the least were accidental. These differences may be due to different religions, believes and cultures. The Islamic law considers suicide to be a crime act onto the self. Thus, the number of SIB may be not reported for fear of legal responsibility and social and religion rejections of this act ${ }^{(16-18)}$.

This high rate of suicidal deaths mainly among women may show the tip of iceberg (underestimated) due to the above mentioned reasons and the social stigma, this denotes a real presence of high priority health and social problem of suicidal burn deaths.

\section{Conclusions}

The case fatality rate of burn injuries was high, females outnumbered males, and suicidal burn deaths were significantly associated with high severity as compared to the accidental.

Ethical Clearance: The Research Ethical Committee at scientific research by ethical approval of both $\mathrm{MOH}$ and MOHSER in Iraq.

\section{Conflict of Interest: None}

Funding: Self-funding 


\section{References}

1. World Health Organization: Burns. World Health Organization: Geneava; 2018.

2. Peck $M$ and Pressman MA: The correlation between burn mortality rates from fire and flame and economic status of countries. Burns 2013;39(6):1054

3. Forjuoh SN. Burns in low- and middle-income countries: a review of available literature on descriptive epidemiology, risk factors, treatment, and prevention. Burns. 2006;32:529-37.

4. Amin PM, Mirlashari J, Nikbakht Nasrabadi A . A cry for help and protest: self-immolation in young kurdishiraqi women -a qualitative study. Int $\mathrm{J}$ Community Based Nurs Midwifery. 2018;6:56-64.

5. Murray CJ, Lopez AD. Measuring the global burden of disease. N Engl J Med. 2013;369:448-57.

6. Peck M, Pressman MA. The correlation between burn mortality rates from fire and flame and economic status of countries. Burns. 2013;39:10549.

7. Saaiq M, Ashraf B. Epidemiology and outcome of self-inflicted burns at pakistan institute of medical sciences, islamabad. World J Plast Surg. 2014;3:107-14.

8. Maghsoudi H, Garadagi A, Jafary GA, Azarmir G, Aali N, Karimian B, Tabrizi M. Women victims of self-inflicted burns in Tabriz, Iran. Burns. 2004;30:217-20.

9. Lama BB, Duke JM, Sharma NP, Thapa B, Dahal $\mathrm{P}$, Bariya ND, Marston W, Wallace HJ. Intentional burns in Nepal: a comparative study. Burns. 2015;41:1306-14.

10. Macedo JL, Santos JB. Predictive factors of mortality in burn patients. Rev Inst Med Trop Sao Paulo. 2007;49:365-70.

11. Laloe V. Epidemiology and mortality of burns in a general hospital of Eastern Sri Lanka. Burns. 2002;28:778-81.

12. Al-Zacko SM. Self-inflicted burns in Mosul: a cross-sectional study. Ann Burns Fire Disasters. 2012;25:121-5.

13. Shabeeb UB. Suicide; A field Social Study in Diqar Governorate. Journal of Babylon Center for Humanities Studies 2020;10(3):21-40

14. Mohammed AAQ The prevalence of burn related deaths in Basrah. The Medical Journal of Basrah
University;2018 36, (1):22-28.

15. Singh A : Epidemiology of Burn and Factors Influencing Mortality in Burn Patients in India. International Journal of Enhanced Research in Medicines \& Dental Care2017; 4;(5):28-33.

16. Hashish RK and Abdel-Karim RI.A Study of Burn Injuries in Patients Admitted to the Burn Unit, Suez Canal University Hospital: Medico-Legal Perspectives. Mansoura J. Forens. Med. Clin. Toxico, 2017; 25(1):79-91

17. Johry A, Mathur Rk and Srivastava A (2015):Study of the Medicolegal Aspects Of Flame Burn Deaths. IRMPS 2015;1(4):35-40

18. Nath A, Das P and Chakraborty PN (2015): Burnt wives of Agartala: a retrospective study from Medicolegal autopsies of a Tertiaty Hospital of Tripura, Northeast India: 2015. Int J Emerg Trends Sci Technol 2015;2(7):2842-2846

19. Kandeel FS. A study of Some Medico-Legal Aspects of Fatal Burn Cases Admitted to Menofia University Hospital over Five Years "A Retrospective Study". Ain Shams Journal of Forensic Medicine and Clinical Toxicology Jan 2019, 32: 57-64.

20. El Mehrat AM, Ghareeb FM, Keshk TF et al.."Retrospective study of mortality and causes of death in Menofia University Burn Center". Menoufia Med. J 2014, 27:290-295

21. Krishnan P, Frew Q, Green A et al. Cause of death and correlation with autopsy findings in burns patients. Burns 2013; 39(4): 583-588.

22. Al-Shamsi M, Othman N. The epidemiology of burns in Basra, Iraq. Ann Burns Fire Disasters. 2017;30(3):167-171.

23. Schaefer, Timothy J., and Karen D. Szymanski. Burns, Evaluation And Management. N.p., 2018. StatPearls. Web.

24. Stiles K. Emergency management of burns: part 2. Emerg Nurse. 2018 Jul;26(2):36-41.

25. McGwin G Jr, George RL, Cross JM, Rue LW. Improving the ability to predict mortality among burn patients. Burns 2008; 34:320-7.

26. Al-Shamsi M, Othman N. The epidemiology of burns in Basra, Iraq. Ann Burns Fire Disasters. 2017 Sep 30;30(3):167-171.

27. LamiFH, Al Naser RK. Epidemiological characteristics of burn injuries in Iraq: A burn hospital-based study. Burns 2019;45(2): 479-483 
28. Bahir Sabah Abood Allawil, HasanAlwan Baiee2, Ameer Hasan Baiee3. (2020). Burn Injury Characteristics and Outcomes among Hospitalized Patients in Tertiary Burn Unit. Medico Legal Update, 20(2), 764-769.

29. Bataineh $\mathrm{Z}$, Alquran $\mathrm{T}$, Al-Balas $\mathrm{H}$, Khammash MR. Pattern of burn injury at north of Jordan. International Journal of Burns and Trauma 2018; $8(1): 1-5$

30. Krishnan P, Frew Q, Green A et al. Cause of death and correlation with autopsy findings in burns patients. Burns 2013; 39(4): 583-588.

31. Dhoble SV, Dere RC, Jaiswani AK, Savardekar RR. Suicidal deaths by burns in females of reproductive age: $2 \mathrm{yr}$ study. Egyptian Journal of Forensic Sciences 2018; 8(3):2-5.

32. Nisavic M, Nejad SH, Beach SR. Intentional Selfinflicted Burn Injuries: Review of the Literature. Psychosomatics. 2017;58(6):581-591.
33. Gatea A, Nedjat S, Yekaninejad MS. Reasons and experiences of self-inflicted burns among women in reproductive age in Baghdad, Iraq: a qualitative study. Int J Burns Trauma. 2019 Jun 15;9(3):73-81.

34. Gadge SJ, Meshram RD, Shrigiriwar MB, Kuchekar SV Epidemiological study of fatal burns cases in SVN government medical college. J Acad Ind Res2014; 2(10):552 -555

35. Gupta R, Kumar V, Tripathi SK. Profile of the fatal burn deaths from the Varanasi region, India. J Clin Diagn Res, 2012, 6(4):608 -611.

36. Vaghela PC, Ahir GN, Patel MH. Epidemiology of fatal burn cases in G.K. General hospital, Bhuj. Natl J Commun Med, 2012 3(2):326 -329.

37. Jeschke MG, Pinto R, Kraft R et al.. Morbidity and survival probability in burn patients in modern burn care. Crit Care Med. 2015, 43(4):808-815.

38. Shinde, Keoliya. "International J. of Healthcare \& Biomedical Research.” April (2013): 227-233. 